\title{
Risk Measure and Early-Warning System of China's Stock Market Based on Price-Earnings Ratio and Price-to-Book Ratio
}

\author{
Rongda Chen, ${ }^{1,2,3}$ Sheng Ye, ${ }^{1}$ and Xianchao Huang ${ }^{4}$ \\ ${ }^{1}$ School of Finance, Zhejiang University of Finance and Economics, Hangzhou 310018, China \\ ${ }^{2}$ Coordinated Innovation Centre of Wealth Management and Quantitative Investment, \\ Zhejiang University of Finance and Economics, Hangzhou 310018, China \\ ${ }^{3}$ Center for Research of Regulation and Policy of Zhejiang, Hangzhou 310018, China \\ ${ }^{4}$ New York Branch, Industrial and Commercial Bank of China, New York, NY 10022, USA \\ Correspondence should be addressed to Rongda Chen; rongdachen@163.com
}

Received 1 December 2013; Accepted 30 January 2014; Published 12 March 2014

Academic Editor: Chuangxia Huang

Copyright (C) 2014 Rongda Chen et al. This is an open access article distributed under the Creative Commons Attribution License, which permits unrestricted use, distribution, and reproduction in any medium, provided the original work is properly cited.

Based on the actual situation of China's stock market, this paper proposes a method for measuring the stock market's risk and early-warning methods which are based on price-to-earnings ratio and price-to-book ratio. The study found that the method of VaR can capture the bigger daily drops in a period, and if the drop is at the periodical top of the index, the probability of a sharp index decline will be very high. It also confirmed that the method is feasible and practical for people to use. In the long run, this method really can send early-warning signals of sharp decline; the warning levels increase as the index rises. The study also found that index will not fall after every warning but will continue going forward because of inertia, particularly during a big trend.

\section{Introduction}

Stock markets around the world are known for fluctuating frequently, but the stock markets in China fluctuate more and they do so more frequently than most other stock markets. High fluctuations adversely affect the real economy as well as the black economy [1]. Firstly, the excessive gains offered by the stock market attract a lot of social capital and reduce availability of funds for production. Secondly, if the stock market forms bubbles, then financial institutions such as banks, insurance companies, and other institutions that are in the center of the financial activities are at the center of the bubble, too. When financial institutions get involved in speculative losses, stability of the entire financial system is adversely affected. High volatility, especially sharp falls shake the confidence of investors in the stock market and reduce the enthusiasm for investment. Finally, when high fluctuations cause heavy losses to enterprises or persons, it can even result in massive unemployment and cause great instability in the society [2]. In addition, high stock market fluctuations result in a series of other problems like a generally weak economic climate and the market's financing function takes a beating. Values of listed companies get distorted and distribution of social wealth too gets twisted, leading to the belief that the concept of social investment is wrong [3]. Therefore, it has become important to effectively measure market risk and find an effective method to ensure an early-warning system.

Currently, there are three main approaches for capturing signals of risk [4]. The first approach is based on the early-warning indicators, represented by probability analysis, climate index analysis, comprehensive index method, and the extended index method. The second approach is based on statistical analysis, represented by sequential discrimination, and discriminant analysis and the third approach is mainly based on econometric models, represented by ARMA warning method, logistic regression analysis, artificial neural network model for early warning and autoregressive conditional heteroskedasticity $\mathrm{ARCH}$, and so forth.

The purpose of signal analysis in the indicator-based early-warning approach is to find out the main mechanism of the risk deterioration process. Namely, analysis of the constraints that impact risk and their interaction and changes 
and the causes which lead to generation of crises provides the basis for formulation of appropriate policies. The core of this method is construction of an overall early-warning indicator system which measures the state of risk and estimates a safe threshold, in accordance with the reasonable state of each discriminant index. Generally speaking, the safety threshold is confirmed in accordance with historical data, but sometimes it is confirmed by subjective judgments, too. Signal analysis is widely used in the indicator-based early-warning method because of its relatively simple concept and easy usage. Based on the KLR signal analysis as a framework, Lin and Song (2011) examined the performance of indicators such as money supply and price-earnings ratio, as early-warning signals of crises in China's stock market [5]. Cao (2009) built an earlywarning model for the Shanghai A-Share Index by using the efficacy coefficient method with various early-warning indicators [6].

Among the modeling approaches, McMillan (2001) used a nonlinear model to predict excessive volatility of stock market and suggested preventive measures [7]. Huang et al. used HAR-CJ-M model to better forecast the volatility of Chinese stock than another two models (HAR-ARV, HAR-CJ) [8]. Xiao (2008) conducted a study on early warnings of crisis in China's stock market by using multiple logit models [9]. Si (2007) used extensive risk evaluation model to identify early warnings of credit risk of China's stock market [10]. Qian and Tao (2009) constructed an appropriate early-warning model for China's stock market by using FED model and taking China's actual situation into consideration [11]. By combining the four models, ARX model, the rough set theory, GM $(1,1)$ model, and the grey relational analysis, Huarng and $\mathrm{Yu}$ (2005) proposed a mixture model to predict the stock index and prevent excessive volatility [12]. Chen et al. (2008) predicted the ups and downs of stock market according to a mixture model of rough set theory and genetic algorithm and proposed corresponding measures to prevent excessive volatility [13].

When calculating VaR of the Shanghai Index, the parameter method is used since computation of volatility is very important. Domestic and foreign scholars have already done a lot of research on volatility models. It is well know that $\mathrm{ARCH}$ and GARCH are the most classic and successful ones [14]. However, the rapid development of computer technology has resulted in significant improvements in existing models and emergence of new models. Wen et al. (2012) revealed the nonlinear properties of the Shanghai stock index by $R / S$ analysis method [15]. ARCH models have been examined extensively by domestic researchers also. Su and Zhan (2005) empirically examined China's stock market and showed that the estimate of VaR under SWARCH model is better than that of the GARCH model [16]. By computing VaR under different distributions of ARMA-GARCH model, Wang (2009) examined the risk of China's interbank market [17]. Based on the GARCH model, Liu and Zhang (2010) used CVaR approach to measure risk of banks, which discussed VaR's inability to measure tail losses properly [18]. Wen and Yang (2009) explored the relationship between the skewness and the coefficient of risk premium of China's composite index by GARCH-M model and the Groeneveld-Meeden method [19]. Jiang (2010) used a semiparametric model for computing VaR of Shanghai stock market [20]. By using several approaches to measure the risk of China's stock market, Tao and $\mathrm{Yu}$ (2009) came to the conclusion that the $\mathrm{VaR}$ approach under MGARCH-BEKK can best explain the risk of China's stock market [21].

Taking into account the issues discussed above in the theories and the actual situations mentioned above and existing literature, it seems that the current existing results in the literature on the early-warning theories are still inadequate and the existing models need adjustment and improvement. For example, the range of applications of models currently being used is not well accepted and there is no standard in the practice for determining the threshold value, and thus they cannot be applied to China's stock market directly. Based on the actual situation of China's stock market, the goal of this paper examines possible ways of measuring market behaviors and devising ways of identifying early-warning signals of excessive volatility of Shanghai Composite Index by using VaR, PE ratio, and PB ratio.

\section{Methodology and Empirical Analysis}

The first task of the paper is to use VaR to set the thresholds or alarm points. If real one-day fall of Shanghai Composite Index exceeds the estimated VaR, the model sees it as risk appearance and sounds alarm. Then we use $\mathrm{P} / \mathrm{E}$ and $\mathrm{P} / \mathrm{B}$ to set risk intervals to measure the index risk level and monitor the changes of index risk.

2.1. Method of $\mathrm{VaR}$. VaR (value at risk) means the maximum probable loss an asset can suffer at a given confidence level. This theory was originally formulated by JPMorgan. The staff of JPMorgan developed an integrated method that can measure different markets and different kinds of assets to satisfy Chairman Weatherstone's need for understanding the general potential losses the company could possibly suffer. VaR is usually expressed as $\operatorname{Pro}(\Delta P>\operatorname{VaR})=1-\alpha$, where " $\alpha$ " is the confidence level.

The paper chooses the Shanghai Composite Index daily return data to study. The data cover a time period of 887 days from May 2007 to April 11, 2011. The logarithm returns ratio is

$$
\text { Rszzs }=\log \left(\operatorname{szzs}_{t}\right)-\log \left(\operatorname{szzs}_{t-1}\right),
$$

where szzs $_{t}$ is the $t$ th Shanghai Composite Index return and Rszzs is the logarithmic return. We use Eviews 6.0 for preparing descriptive statistics of the time series of Shanghai Composite Index return after excluding some days when the market did not open. Descriptive statistics are listed in Table 1 and Figure 1.

The paper uses the ADF test to examine the stationarity of the time series of return of Shanghai Composite Index for avoiding spurious regression. If the $P$ value of $\mathrm{ADF}$ test is less than 0.5 , the null hypothesis that the series is steady is rejected; if $P$ value is greater than 0.5 , the null hypothesis that the series is nonstationary is accepted. The results show that series data are stationary. So we can use the model directly, 
TABle 1: Time series of Shanghai Composite Index return descriptive statistics.

\begin{tabular}{cccccccc}
\hline & Number & Mean & Max & Min & Std. Dev. & Kurtosis & Skewness \\
\hline Rszzs & 887 & -0.000131 & 0.039235 & -0.055431 & 0.009687 & 5.572005 & -0.388196 \\
\hline
\end{tabular}

Data sources: Founder Securities Flush Market analysis system.

TABLE 2: Time series of Shanghai Composite Index return unit root test.

\begin{tabular}{lcccc}
\hline Series & ADF & $1 \%$ criticality value & Prob. & Conclusion \\
\hline Rszzs & -30.84600 & -3.437508 & 0.0000 & stationarity \\
\hline
\end{tabular}

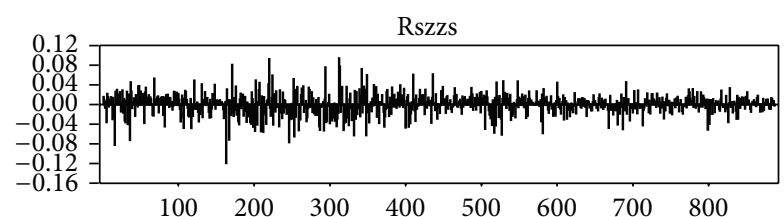

FIGURE 1: Shanghai Composite Index fluctuations' descriptive statistics.

without cointegration. Previous studies have demonstrated that the time series of stocks have special properties like being nonnormal, sharp peaked, and heavy tailed and $t$ distribution has a thick tail. To test this view, this paper examines the time series of return of Shanghai Composite Index (see Table 2).

Figure 2 shows that the $t$-distribution can describe the time series of return of Shanghai Composite Index better than normal distribution. So we assume that stock yield sequence obeys student's $t$-distribution in the later analysis.

Table 3 shows that series of Shanghai Composite Index returns show first-order autocorrelation at 0.95 confidence level. But we find that the regression coefficient is not significantly different from $0(P=0.284)$ after using Rszzs and Rszzs $(-1)$ to regress directly. So we believe that the series of Shanghai Composite Index returns do not have an ARMA term but may have the GARCH effect. We use unitary $\operatorname{GARCH}(1,1)$ model under $t$-distribution to estimate conditional variance of Shanghai Composite Index [22]:

$$
\begin{gathered}
y=c+u_{t}, \\
\frac{u_{t} \mid \psi_{t-1}}{\sigma_{t}} \sim T(v), \\
\sigma_{t}^{2}=\alpha_{0}+\alpha_{1} u_{t-1}^{2}+\beta_{1} \sigma_{t-1}^{2}, \\
\left(\alpha_{0}>0, \alpha_{1} \geq 0, \beta_{1} \geq 0\right) .
\end{gathered}
$$

So the equation for estimation of variance of the unitary $\operatorname{GARCH}(1,1)-t$ model is of the following form:

$$
\sigma_{t}^{2}=2.83 E-7+0.049584 u_{t-1}^{2}+0.949512 \sigma_{t-1}^{2} .
$$

According to the characteristics of $t$-distribution, we first calculate $t$-distribution at $95 \%$ and $99 \%$ quantiles. The quantile of 5.181459088 degrees of freedom of unitary $\operatorname{GARCH}(1,1)-T$ model at 0.95 confidence level
TABle 3: Correlation test of the time series of Shanghai Composite Index return.

\begin{tabular}{lcccc}
\hline Leg & AC & PAC & Q-Stat & Prob. \\
\hline 1 & -0.516 & -0.516 & 236.43 & 0.000 \\
2 & -0.012 & -0.378 & 236.55 & 0.000 \\
3 & 0.045 & -0.251 & 238.39 & 0.000 \\
4 & -0.008 & -0.182 & 238.45 & 0.000 \\
5 & 0.002 & -0.129 & 238.45 & 0.000 \\
6 & -0.032 & -0.149 & 239.35 & 0.000 \\
7 & 0.048 & -0.082 & 241.39 & 0.000 \\
8 & -0.066 & -0.147 & 245.32 & 0.000 \\
9 & 0.048 & -0.113 & 247.35 & 0.000 \\
10 & -0.010 & -0.105 & 247.44 & 0.000
\end{tabular}

Note: the Q-Stat expression is of the form $Q=T(T+2) \sum\left(r_{j}^{2} / T-j\right)$. Null hypothesis: series has $P$-order autocorrelation. Alternative hypothesis: series does not have $P$-order autocorrelation. Table 4 shows the ten-order lagged result of every series.

TABLE 4: Result of unitary GARCH $(1,1)$ model parameter estimates on student's $t$-distribution.

\begin{tabular}{lcccc}
\hline Variable & Coefficient & Std. error & $z$-Statistic & Prob. \\
$\alpha_{0}$ & 0.000538 & 0.000253 & 2.128060 & 0.0333 \\
\hline \multicolumn{5}{c}{ Variance equation } \\
$\alpha_{0}$ & $2.83 E-07$ & $4.20 E-07$ & 0.674479 & 0.5000 \\
RESID $(-1)^{\wedge} 2$ & 0.049584 & 0.013664 & 3.628747 & 0.0003 \\
GARCH(-1) & 0.949512 & 0.013671 & 69.45407 & 0.0000 \\
T-DIST. DOF & 5.181459 & 0.871401 & 5.946123 & 0.0000 \\
\hline
\end{tabular}

Note: GARCH $=\alpha_{0}+\alpha_{1}{ }^{*} \operatorname{RESID}(-1)^{\wedge} 2+\beta_{1} * \operatorname{GARCH}(-1)$.

" $E-7$ " means " $10 *(-7)$ ".

is 1.999564055233011; at 0.99 confidence level it is 1.999564055233011. So the $t$ day $\operatorname{VaR}$ value $=$ the $(t-1)$ day closing price $* \mathrm{VaR}$ of Shanghai Composite Index $\mathrm{VaR}$ of the trading day and the expression is of the form $\mathrm{VaR}=\mathrm{P} 0 * \alpha \sigma$.

The number of days when the theory fails is compared with calculations for evaluation of model quality; that is, the smaller the difference, the better. Table 5 shows the contrast of failure days of unitary $\operatorname{GARCH}(1,1)-T$ model under 0.95 and 0.99 confidence levels.

Table 5 shows that, although $t$-distribution can describe the steep peaks and heavy tails, the estimated value of VaR under $t$-distribution hypothesis is relatively conservative, as it relatively overestimates the risk. 

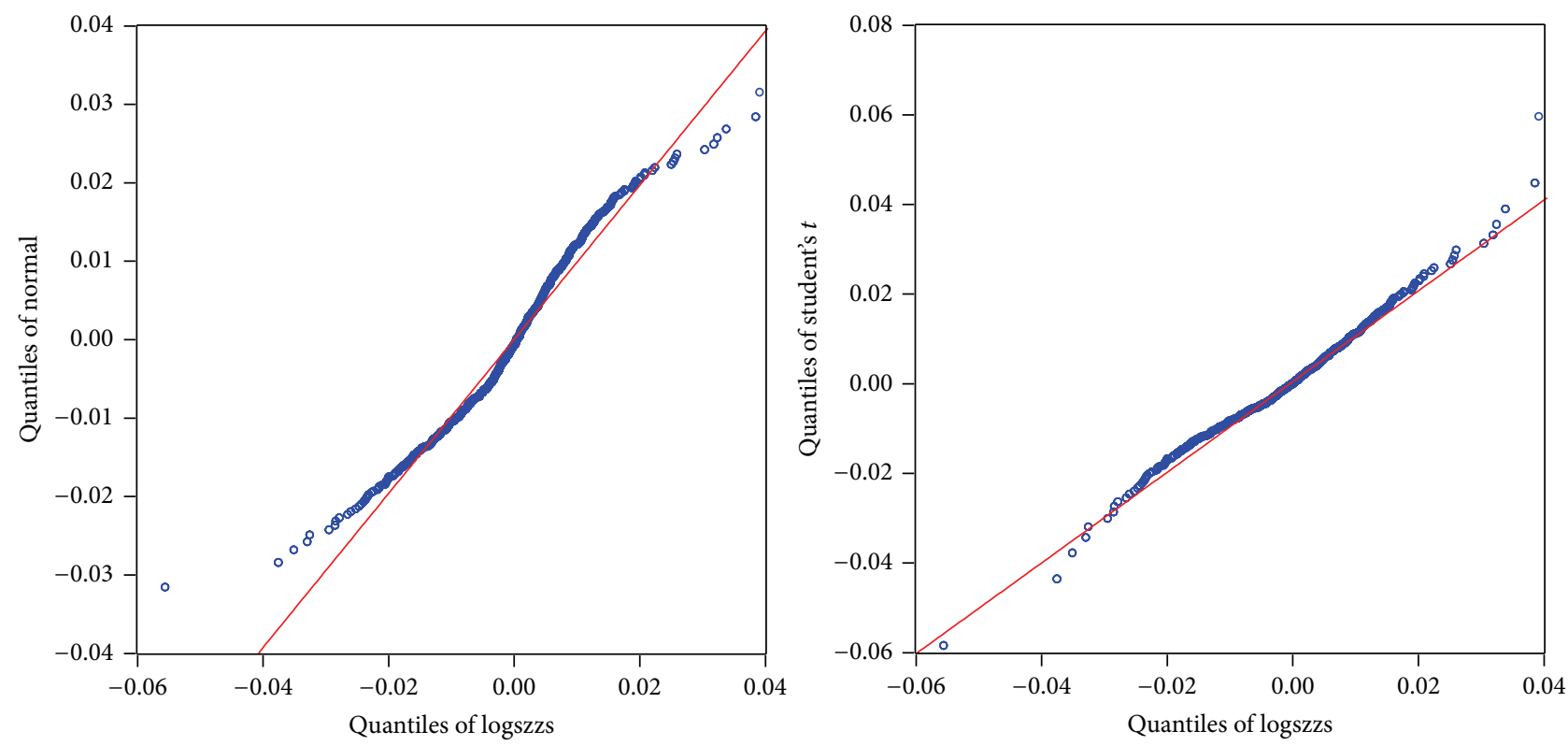

FIGURE 2: Index yield distribution $Q Q$ test pattern.

TABLE 5: Statistical characteristic and backtesting of different confidence level $t$-distribution VaR values.

\begin{tabular}{lccccccc}
\hline Model & $\begin{array}{c}\text { Confidence level } \\
(\%)\end{array}$ & $\begin{array}{c}\text { VaR } \\
\text { Min }\end{array}$ & $\begin{array}{c}\text { VaR } \\
\text { Max }\end{array}$ & $\begin{array}{c}\text { VaR mean } \\
\text { meary }\end{array}$ & $\begin{array}{c}\text { Theory } \\
\text { failure }\end{array}$ & $\begin{array}{c}\text { Actual } \\
\text { failure } \\
\text { rate } \\
(\%)\end{array}$ \\
\hline GARCH(1,1)- $t$ & 95 & -0.0097 & -0.0323 & -0.0190 & 44 & 34 \\
GARCH(1,1)- $t$ & 99 & -0.0161 & -0.0536 & -0.0094 & 8 & 7.833 \\
\hline
\end{tabular}

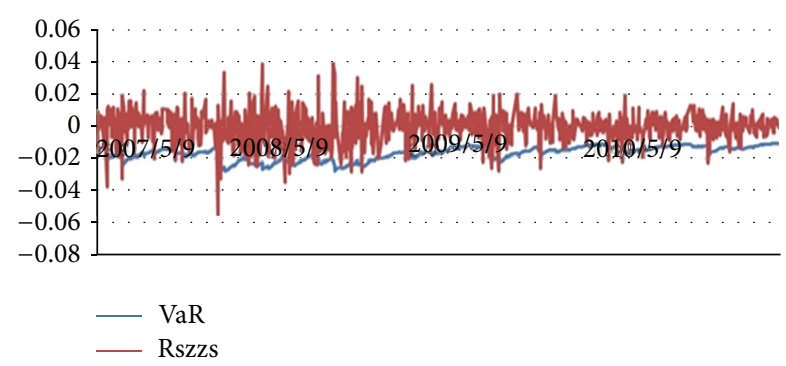

FIGURE 3: 95\% confidence level unitary $\operatorname{GARCH}(1,1)-t$ model daily VaR.

Figure 3 shows that the number of times when actual VaR is beyond the estimated value at the $95 \%$ confidence level is 34.

Each instance of actual value going beyond the estimated value is viewed as an alarm. Then we combine VaR, $\mathrm{P} / \mathrm{E}$, and $\mathrm{P} / \mathrm{B}$ into a unit to build the Shanghai Composite Index synthetic warning model.

2.2. Price-to-Earnings Ratio Index. Price-to-earnings ratio ( $\mathrm{PE}$ or $\mathrm{P} / \mathrm{E}$ ) refers to the ratio of stock price and earnings per share; that is, $\mathrm{P} / \mathrm{E}$ equals market price per common share divided by earnings per common stock per year. The $\mathrm{P} / \mathrm{E}$ of the stock market generally equals the total value of the market capitalization divided by the sum of earnings per share multiplied by the total number of equity shares. In general, stocks with high $\mathrm{P} / \mathrm{E}$ are believed to be overvalued, thus indicating a bubble, while extraordinarily low $\mathrm{P} / \mathrm{E}$ indicates undervaluation. $\mathrm{P} / \mathrm{E}$ index is easy to follow and the data is easy to get, so it is usually applied for evaluation of the stocks and the market. The general formula for calculating the reasonable $\mathrm{P} / \mathrm{E}$ is

$$
V=k \times \sum \frac{(-\mathrm{PMt})}{(1+R)^{t}},
$$

where $k$ represents the firm's dividend, $\mathrm{Mt}$ is the growth rate of earnings per share, and $R$ is the expected rate of return. The approximate formula is $V=\mathrm{Mt} / \mathrm{Rt}$. As for the broader market, the P/E mainly depends on the level of the expected return rate. According to CAPM model $\mathrm{Ri}=\mathrm{Rf}+$ $\beta \mathrm{i}(\mathrm{Rm}-\mathrm{Rf})$, the expected return rate equals the market riskfree return plus the risk premium.

The risk-free return rates generally refer to one-year bonds. However, for the determination of risk premium, different scholars hold different views. Therefore, the definition of a reasonable $\mathrm{P} / \mathrm{E}$ for China's stock market varies. For example, $\mathrm{Yu}$ and $\mathrm{Hu}$ (2011) argue that the reasonable P/E for the Shanghai Composite Index in 2007 was about 32 while Zhang thought it was 25.36 [23]. Obviously there are no uniform parameters for calculating the reasonable $\mathrm{P} / \mathrm{E}$ and the calculation results may not be accurate. 
TABLE 6: P/E contrast of China's stock market and foreign ones.

\begin{tabular}{|c|c|c|c|c|c|c|}
\hline Year & $\begin{array}{c}\text { Shanghai } \\
\text { Composite Index }\end{array}$ & Dow Jones Index & $\begin{array}{c}\text { Financial Times } \\
\text { Ordinary Shares Index }\end{array}$ & Hang Seng Index & $\begin{array}{c}\text { Korea Stock Price } \\
\text { Index }\end{array}$ & $\begin{array}{c}\text { Taiwan Weighted } \\
\text { Index }\end{array}$ \\
\hline 1995 & 15.70 & 13.89 & 15.60 & 11.40 & 16.60 & 21.30 \\
\hline 1996 & 31.32 & 15.71 & 16.20 & 16.70 & 18.00 & 29.00 \\
\hline 1997 & 39.86 & 18.58 & 19.20 & 12.10 & 9.80 & 27.00 \\
\hline 1998 & 34.38 & 21.88 & 23.30 & 10.70 & 27.80 & 26.10 \\
\hline 1999 & 38.13 & 25.13 & 30.50 & 26.70 & 34.60 & 47.70 \\
\hline 2000 & 58.22 & 22.85 & 23.30 & 12.80 & 15.40 & 14.80 \\
\hline 2001 & 37.71 & 31.06 & 20.30 & 12.20 & 29.30 & 41.60 \\
\hline 2002 & 34.43 & 29.00 & 17.70 & 14.90 & 15.60 & 41.80 \\
\hline 2003 & 36.54 & 27.88 & 18.30 & 19.00 & 10.10 & 24.80 \\
\hline 2004 & 24.23 & 20.44 & 14.70 & 18.70 & 15.80 & 12.60 \\
\hline 2005 & 16.33 & 18.85 & 14.00 & 15.60 & 11.00 & 17.60 \\
\hline 2006 & 33.30 & 18.16 & 13.40 & 17.40 & 11.40 & 19.00 \\
\hline 2007 & 48.50 & 25.48 & 11.80 & 22.50 & 16.80 & 15.30 \\
\hline 2008 & 14.85 & 16.13 & 6.30 & 7.30 & 9.00 & 9.80 \\
\hline 2009 & 28.78 & 18.73 & 16.80 & 18.10 & 23.70 & 110.5 \\
\hline Mean & 33.53 & 21.58 & 17.43 & 15.74 & 17.66 & 30.59 \\
\hline Std. Dev. & 13.19 & 5.16 & 5.66 & 4.96 & 7.81 & 24.81 \\
\hline
\end{tabular}

Besides, the reasonable $\mathrm{P} / \mathrm{E}$ is just a value instead of a range, so it is of little significance to calculate the theoretically reasonable $\mathrm{P} / \mathrm{E}$ for setting an early-warning range in this paper.

In fact, the $\mathrm{P} / \mathrm{E}$ of China's stock market has always been high. The average $\mathrm{P} / \mathrm{E}$ of the Shanghai Composite Index from 1982 to July 2005 was 38.87 . In some bull markets, the P/E is as high as 50 to 60 times.

As Table 6 shows, when compared with China, $\mathrm{P} / \mathrm{E}$ ratios of the developed world markets have generally been lower. This surely has something to do with the fact that economic growth of developed countries is slowing down. For example, economic growth of the United States was about 3\% over the past decades, while its $\mathrm{P} / \mathrm{E}$ has been below 20 in most of the times. Even in 2007 when the US stocks rose sharply, P/E was below 30 and it went back to 16 after the subprime mortgage crisis. As an emerging economy and a widely recognized world economic engine, China's economy grew basically at a rate of more than $7 \%$ in the past 20 years, so it is somewhat reasonable that the $\mathrm{P} / \mathrm{E}$ of China's stock market is slightly high.

However, the mean P/E (which is 33.53) of the Shanghai Composite Index still seems too high. This is attributable to the following factors: (a) the valuable "listing qualification," (b) high proportion of retail investors, and (c) the fact that there is no mechanism for short selling. The valuable "listing qualification" makes the ST junk companies, which should be delisted in the market, be merged to another company which has no other opportunity such as IPO to be public, so that they can cast off their old self, which blocks the stock price from falling. But this situation is changing. China's stock market is dominated by retail investors and one of the important features is that investors do not sell at a price lower than the cost. As a result, the cost of acquisition has been

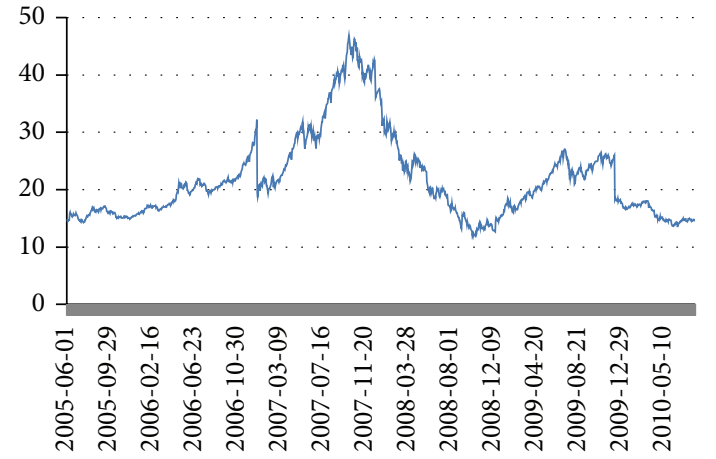

FIgure 4: Shanghai Composite Index daily P/E historical data.

increasing and so have been the valuations. However, stock index futures have been launched nowadays, and the shortselling mechanism has been introduced into the market, which may curb the excessively high $\mathrm{P} / \mathrm{E}$. Moreover, there is little possibility of China maintaining high economic growth forever. The growth of China's economy is slowing down and is inevitable and the market will certainly respond to that. In fact, there is a downward trend in average $\mathrm{P} / \mathrm{E}$ in the China's stock market now.

China's stock market is expected to mature theoretically, so the paper mainly analyzes the Shanghai Composite Index $\mathrm{P} / \mathrm{E}$ historical data from May 9, 2005, when the stock right splitting reform has been finished, to September 3, 2010, and it tries to set an early-warning standard.

Figures 4 and 5 show that the mean P/E of the Shanghai Composite Index is 21.73 with standard deviation of about 7.45, since May 9, 2005, while the Index has $\mathrm{P} / \mathrm{E}$ in the range 


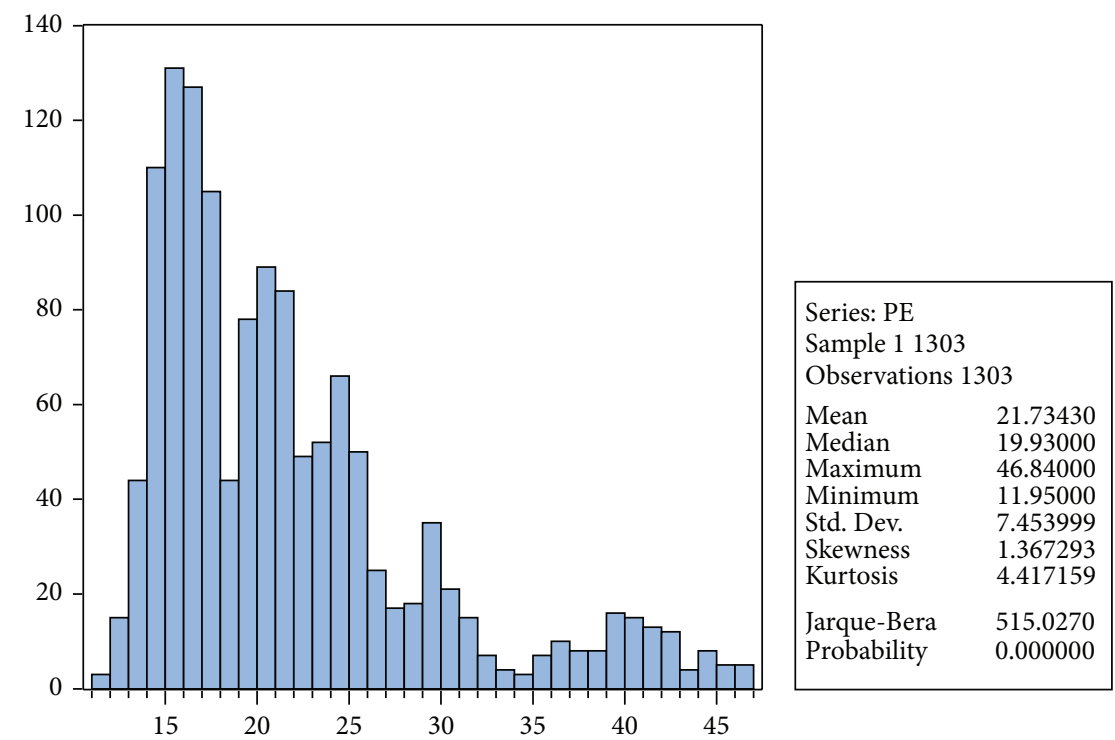

FIGURE 5: Shanghai Composite Index daily P/E descriptive statistics.

of 15 to 25 . When the $\mathrm{P} / \mathrm{E}$ of the index is higher than 25 , it is always followed by a large drop; when the P/E of the index is lower than 15 , the index always tends to be stable or bottoms out. Therefore, we attempt to regard 21.73 as the dividing line and allow it to float with a standard deviation of 1.5 as the early-warning range. When the index $\mathrm{P} / \mathrm{E}$ is below 10.55 , we believe that the market risk is minimal or there is little risk; when the $\mathrm{P} / \mathrm{E}$ is between 10.55 and 21.73 , the market risk is relatively small and, when the $\mathrm{P} / \mathrm{E}$ is between 21.73 and 32.91, there is some risk of the market moving downwards; that is, this is the point where attention is needed. Thus we set number 1 as the alarm; when the $\mathrm{P} / \mathrm{E}$ is more than 32.91 times, we believe that there is a great risk in the market, which should warn the investors, and thus we set number 2 as the alarm.

2.3. Price-to-Book Ratio Index. The price-to-book ratio index refers to the ratio of stock price and its net assets per share. Like the price-earnings ratio data, the price-to-book ratio data can also be found on the major economic and financial websites and in the trading software. It is easy to follow, so it is widely used. The price-to-book ratio can reflect the premium of a stock well. The higher the ratio, the lower the stock value. In the meantime, the lower the ratio, the higher the return on investment; the paper assumes that the firm's income is constant. In general, a stock with a relatively low ratio has a high investment value. On the contrary, a stock with a relatively high ratio has a low investment value. Calculation of the price-to-book ratio can be described as follows: $\mathrm{P} / \mathrm{B}$ (ratio) = price share/book value. That is, $\mathrm{P} / \mathrm{B}$ equals the market price per common stock divided by net assets per common stock at a given point of time.

Likewise, the paper selects the Shanghai Composite Index P/B historical data from May 9, 2005, when the stock right splitting reform had been finished, to September 3, 2010, to analyze and try to set the warning range.

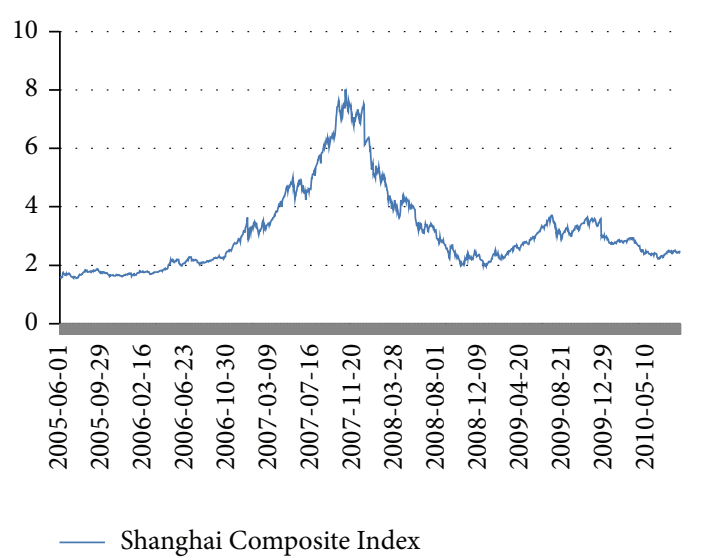

FIgURE 6: Shanghai Composite Index P/B historical data.

Figures 6 and 7 show that the mean P/B of the Shanghai Composite Index is 3.133 since May 9, 2005, stock right splitting reform. Combined with the market trend, we find that the trend of the Shanghai Composite Index is relatively stable around a $\mathrm{P} / \mathrm{B}$ ratio of 3.133 and the volatility is small, with less risk. When the $\mathrm{P} / \mathrm{B}$ is more than 3 times, it is probable that it would fall sharply. When the index $\mathrm{P} / \mathrm{B}$ is around 2 times, it always tends to be stable or at the bottom. So we set 3.133 times $\mathrm{P} / \mathrm{B}$ value as the middle risk line of the index and allow the $\mathrm{P} / \mathrm{B}$ value to float with 0.7 standard deviation as the risk range. When the index $\mathrm{P} / \mathrm{B}$ is below 2.132, the market risk is minimal or there is little risk; when the index $\mathrm{P} / \mathrm{B}$ is between 2.1232 and 3.1233, the market risk is relatively small; when the index $\mathrm{P} / \mathrm{B}$ is between 3.1233 and 4.1234 , there is some risk in the market, and thus we set number 1 as the alarm; when the index $\mathrm{P} / \mathrm{B}$ is higher than 4.1234 , there is great risk in the market, which calls for investors' attention, and thus we set number 2 as the alarm. 


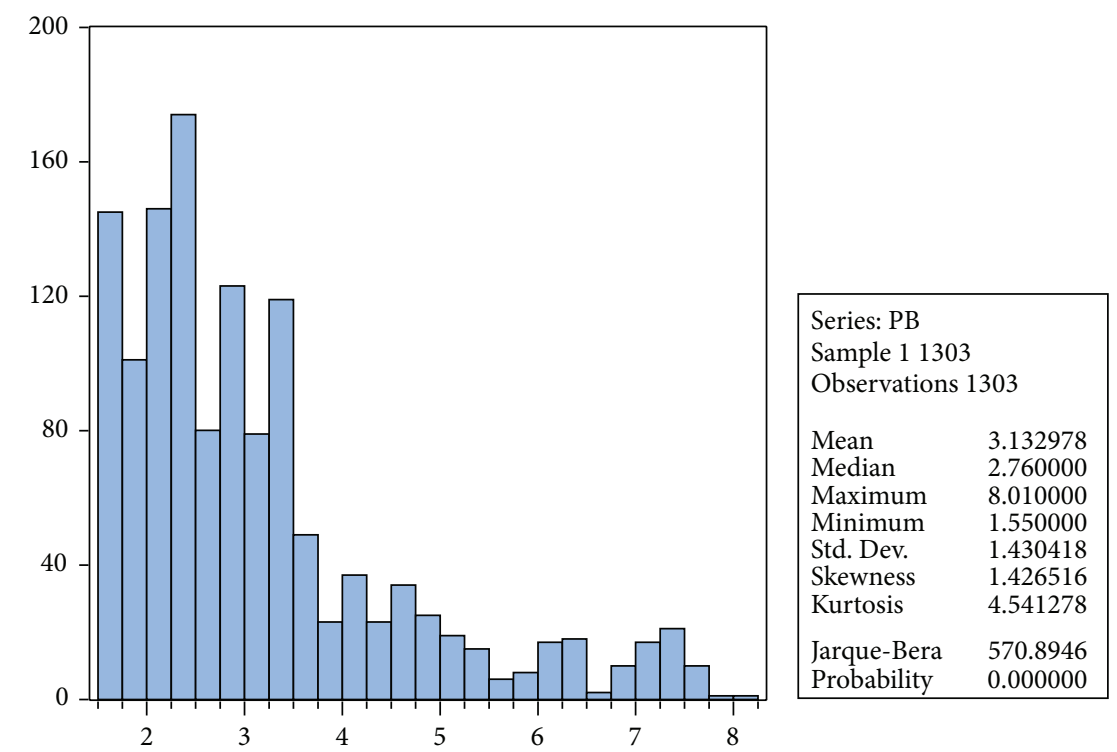

FIgURE 7: Shanghai Composite Index P/B descriptive statistics.

TABLE 7: Shanghai Composite Index early-warning table.

\begin{tabular}{|c|c|c|c|c|c|c|c|c|c|}
\hline Date & $\mathrm{P} / \mathrm{E}$ alarm & $\mathrm{P} / \mathrm{B}$ alarm & $\mathrm{RC}$ & Index & Date & $\mathrm{P} / \mathrm{E}$ alarm & P/B alarm & $\mathrm{RC}$ & Index \\
\hline $2007 / 05 / 15$ & 1 & 2 & 3 & Up & $2009 / 02 / 18$ & 0 & 0 & 0 & Up \\
\hline $2007 / 06 / 04$ & 1 & 2 & 3 & Up & $2009 / 02 / 24$ & 0 & 0 & 0 & Down \\
\hline 2007/07/05 & 1 & 2 & 3 & Up & $2009 / 04 / 08$ & 0 & 0 & 0 & Up \\
\hline 2007/09/11 & 2 & 2 & 4 & Up & $2009 / 07 / 29$ & 1 & 1 & 2 & Down \\
\hline 2007/10/18 & 2 & 2 & 4 & Down & $2009 / 08 / 12$ & 1 & 1 & 2 & Down \\
\hline $2007 / 10 / 25$ & 2 & 2 & 4 & Down & 2009/08/17 & 1 & 0 & 0 & Down \\
\hline 2007/11/08 & 2 & 2 & 4 & Down & $2009 / 09 / 01$ & 0 & 0 & 0 & Up \\
\hline 2008/01/22 & 1 & 2 & 3 & Down & $2009 / 11 / 24$ & 1 & 1 & 2 & Down \\
\hline 2008/01/28 & 1 & 2 & 3 & Down & $2009 / 11 / 27$ & 1 & 1 & 2 & Down \\
\hline $2008 / 03 / 27$ & 1 & 1 & 2 & Down & $2010 / 04 / 19$ & 0 & 0 & 0 & Down \\
\hline 2008/04/09 & 1 & 1 & 2 & Down & $2010 / 05 / 06$ & 0 & 0 & 0 & Down \\
\hline 2008/06/10 & 0 & 1 & 1 & Down & $2010 / 05 / 17$ & 0 & 0 & 0 & Down \\
\hline 2008/06/19 & 0 & 1 & 1 & Down & $2010 / 06 / 29$ & 0 & 0 & 0 & Up \\
\hline 2008/08/11 & 0 & 0 & 0 & Down & 2010/11/12 & 0 & 0 & 0 & Down \\
\hline 2008/10/27 & 0 & 0 & 0 & Down & $2010 / 11 / 16$ & 0 & 0 & 0 & Down \\
\hline 2008/11/18 & 0 & 0 & 0 & Up & $2010 / 12 / 29$ & 0 & 0 & 0 & Down \\
\hline $2008 / 12 / 23$ & 0 & 0 & 0 & Down & & & & & \\
\hline
\end{tabular}

Note: date stands for the date of the index actual drop exceeding the value of VaR. RC stands for risk accumulation. Index stands for the situation of the Shanghai Composite Index running afterwards.

TABLE 8: Analysis and summaries of the risk warning of SSE Composite Index.

\begin{tabular}{|c|c|c|}
\hline & Risk accumulation $=0$ & Little risk in big falls of index and thus little risk and high probability of profiting in investment. \\
\hline VaR no warning & Risk accumulation $\geq 1$ & $\begin{array}{l}\text { Investment risk exists. The higher the risk accumulation is, the more risk exists in investment. } \\
\text { Long-term investors should adjust their investments according to the risk accumulation. }\end{array}$ \\
\hline VaR warning & Risk accumulation $=0$ & $\begin{array}{l}\text { SSE Composite Index rises } 5 \text { times and falls } 11 \text { times among } 16 \text { VaR risk warnings. } \\
\text { Probabilistically, short-term investors should leave and wait temporarily, while long-term } \\
\text { investors can still invest as the market is in a low-risk position. }\end{array}$ \\
\hline VaR warning & Risk accumulation $\geq 1$ & $\begin{array}{l}\text { Index falls sharply } 13 \text { times among } 17 \mathrm{VaR} \text { risk warnings. Probabilistically, short-term investors } \\
\text { should leave and wait, while long-term investors should continue reducing their investments } \\
\text { and ultimately get completely short positions with the increase of cumulative risks }\end{array}$ \\
\hline
\end{tabular}


We use the VaR method and regard the date when the drop in the Shanghai Composite Index exceeds the VaR as the alarm date. Combining with the above $\mathrm{P} / \mathrm{E}$ and $\mathrm{P} / \mathrm{B}$ indices, we establish a Shanghai Composite Index early-warning table as described in Tables 7 and 8.

\section{Conclusion}

In conclusion, our study shows the following.

In the short term, it is possible to take advantage of risk warning spots where the actual index decline exceeds VaR. Usually the market goes for a relatively big adjustment after the index's first sudden and sharp decline beyond VaR, without any exception, even in 07's hot market. Warning spots usually come during these sharply dropping days. This indicates that, on the one hand, market adjusting after a fall has already been an event of great probability and, on the other hand, it is practical to utilize VaR to alarm the index briefly.

In the long run, it seems that, by considering the effects of adopting an integral warning method combining VaR with $\mathrm{P} / \mathrm{E}$ and $\mathrm{P} / \mathrm{B}$, our method could give an early warning before a great fall of the index, whose warning intensity is progressive and results accord with real index performance. But given the inertia of performance itself, we find that the index does not fall for sure after all warnings; by contrast, it may still run as before for some time. This could be explained that, in big trends, especially, it is more likely that the market runs with inertia.

\section{Conflict of Interests}

The authors declare that they have no conflict of interests.

\section{Acknowledgment}

This research was supported by the National Natural Science Foundation of China (Grant no. 71171176).

\section{References}

[1] X. Liao, The Formation Mechanism and Prevention of Bubble Economy, Economic Management Press, 2008.

[2] Z.-T. Yin, "The outbreak of the first financial crisis in the Republic of China and its inspiration," Journal of Shandong Institute of Business and Technology, vol. 23, no. 1, pp. 80-86, 2009.

[3] C.-J. Hu and Q.-W. Liang, "The thinking about China's stock market by a wide margin rising and sharply slumping," Special Journal of Zone Economy, vol. 11, pp. 59-64, 2010.

[4] G. Sun, Theory and Empirical Analysis of Stock Market Crisis Warning of Our Country, Tianjin University of Finance \& Economics, 2001.

[5] X.-W. Lin and B.-Q. Song, "Early warning model by empirical analysis of financial risk in China," Journal of Fuzhou University, vol. 4, pp. 8-49, 2011.

[6] J.-F. Cao, "Warning index construction and empirical analysis of speculative stock market bubble," China Management Informationization, vol. 12, no. 9, pp. 21-28, 2009.
[7] D. G. McMillan, "Nonlinear predictability of stock market returns: evidence from nonparametric and threshold models," International Review of Economics and Finance, vol. 10, no. 4, pp. 353-368, 2001.

[8] C.-X. Huang, X. Gong, X.-H. Chen, and F.-H. Wen, "Measuring and forecasting volatility in Chinese stock market using HARCJ-M model," Abstract and Applied Analysis, vol. 2013, Article ID 143194, 13 pages, 2013.

[9] C.-S. Xiao, "A study of the stock market crisis early-warning system," Southwest Jiaotong University, vol. 38, no. 7, pp. 76-82, 2008.

[10] Y. Si, “The applied research of extension comprehensive evaluation of our stock market risk early warning," Market Modernization, vol. 19, no. 8, pp. 121-128, 2007.

[11] L. Qian and Y.-M. Tao, "The precaution mechanism of $\mathrm{P} / \mathrm{E}$ multiple on the burst of the stock market bubble," Journal of Donghua University, vol. 36, no. 4, pp. 83-89, 2009.

[12] K. Huarng and H.-K. Yu, "A type 2 fuzzy time series model for stock index forecasting," Physica A, vol. 353, no. 1-4, pp. 445$462,2005$.

[13] T.-L. Chen, C.-H. Cheng, and H.-J. Teoh, "High-order fuzzy time-series based on multi-period adaptation model for forecasting stock markets," Physica A, vol. 387, no. 4, pp. 876-888, 2008.

[14] T. Bollerslev, "Generalized autoregressive conditional heteroskedasticity," Journal of Econometrics, vol. 31, no. 3, pp. 307327, 1986.

[15] F.-H. Wen, Z. Li, C.-H. Xie, and S. David, "Study on the fractal and chaotic features of the Shanghai composite index," FractalsComplex Geometry Patterns and Scaling in Nature and Society, vol. 20, no. 2, pp. 133-140, 2012.

[16] T. Su and Y.-R. Zhan, "VaR estimation based on SWARCH model," Journal of Quantitative \& Technical Economics, vol. 12, pp. 15-24, 2005.

[17] D.-Q. Wang, "ARMA-GARCH models and the appl ication of VaR method to Chinese inter-bank borrowing interest rate," Journal of Systems Engineering, vol. 5, no. 27, pp. 12-19, 2009.

[18] Q.-Z. Liu and N.-F. Zhang, "Research on credit risk CVaR measurement method based on GARCH model," Journal of Statistics and Decision, vol. 10, pp. 56-61, 2010.

[19] F. Wen and X. Yang, "Skewness of return distribution and coefficient of risk premium," Journal of Systems Science \& Complexity, vol. 22, no. 3, pp. 360-371, 2009.

[20] T. Jiang, “The measurement and analysis of stock market risk based on GARCH model \& David X.L1999 and VaR method: the empirical evidence from Shanghai stock market," Journal of Financial Research, vol. 78, no. 6, pp. 132-143, 2010.

[21] A.-Y. Tao and Z.-Y. Yu, "The contrastive analysis of financial market risk measurement method," Statistics and Decision, vol. 46, no. 8, pp. 37-43, 2009.

[22] C. Pérignon, Z. Y. Deng, and Z. J. Wang, "Do banks overstate their Value-at-Risk?" Journal of Banking and Finance, vol. 32, no. 5, pp. 783-794, 2008.

[23] Y. Yu and X.-K. Hu, "An Empirical Study of China's stock market theory p/e ratio," Journal of Economic Vision, vol. 6, pp. 33-35, 2011. 


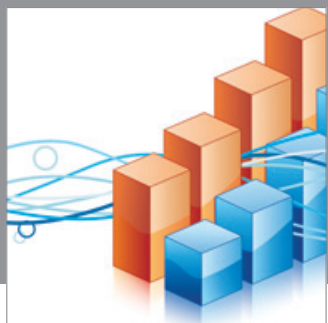

Advances in

Operations Research

mansans

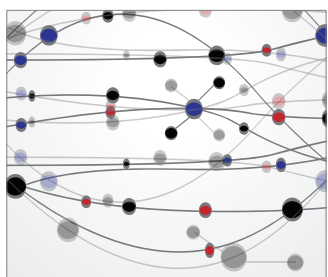

The Scientific World Journal
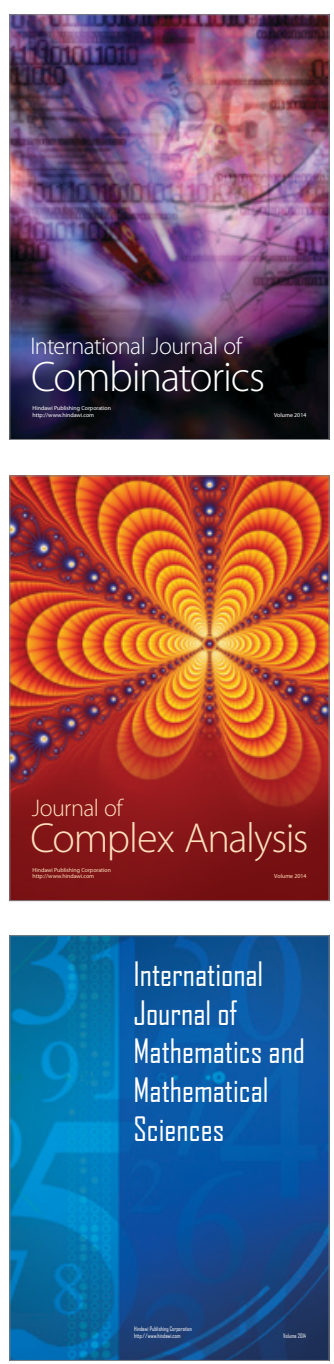
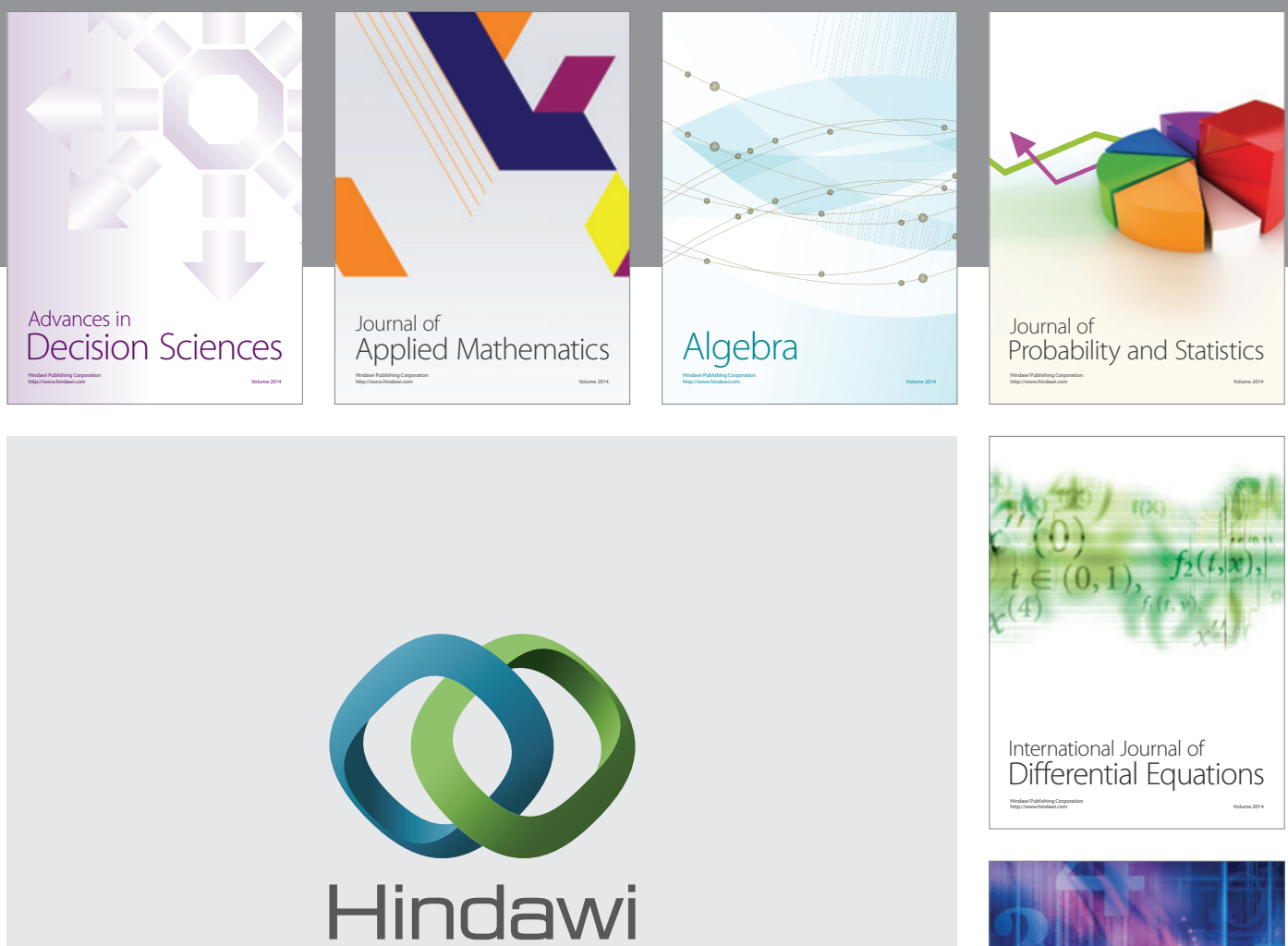

Submit your manuscripts at http://www.hindawi.com
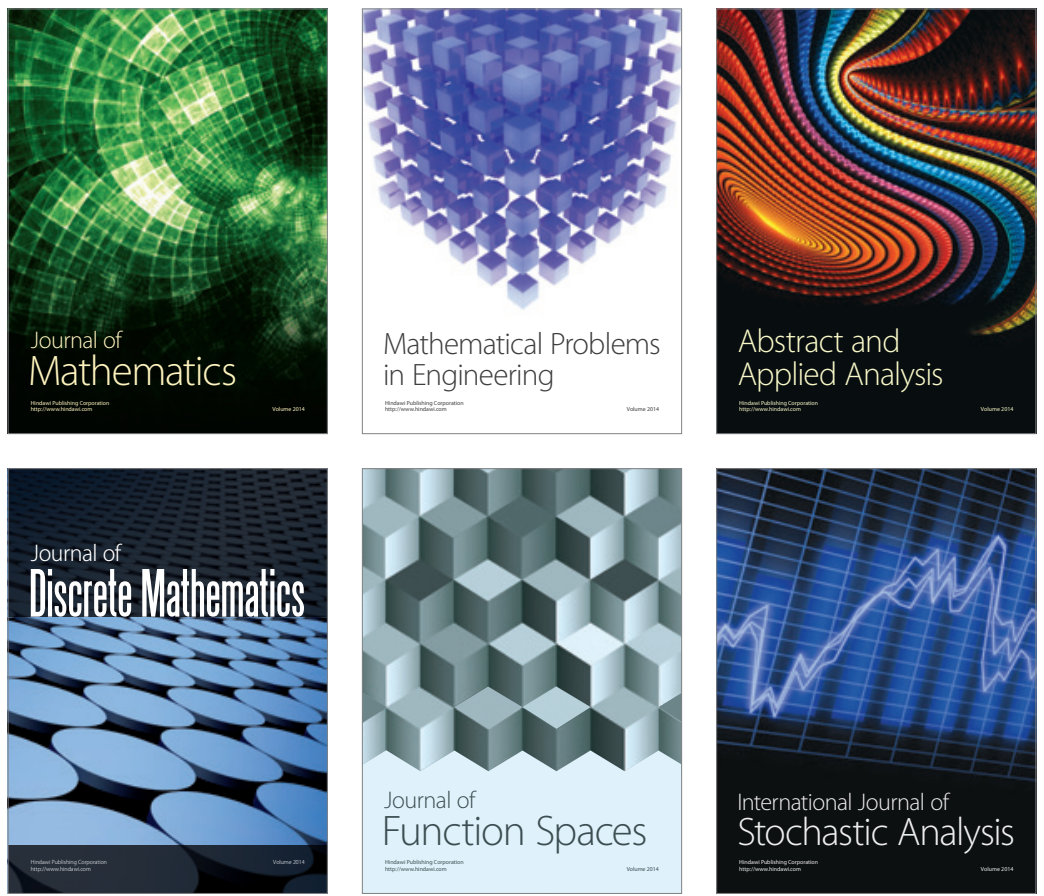

Journal of

Function Spaces

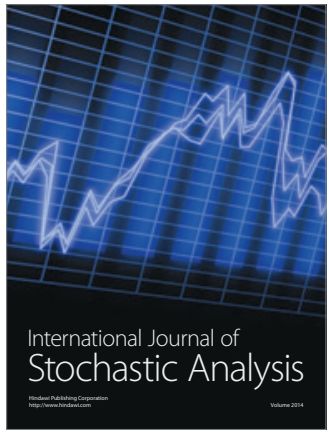

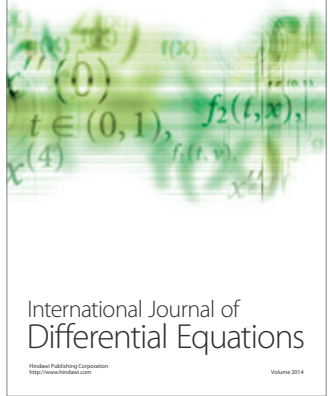
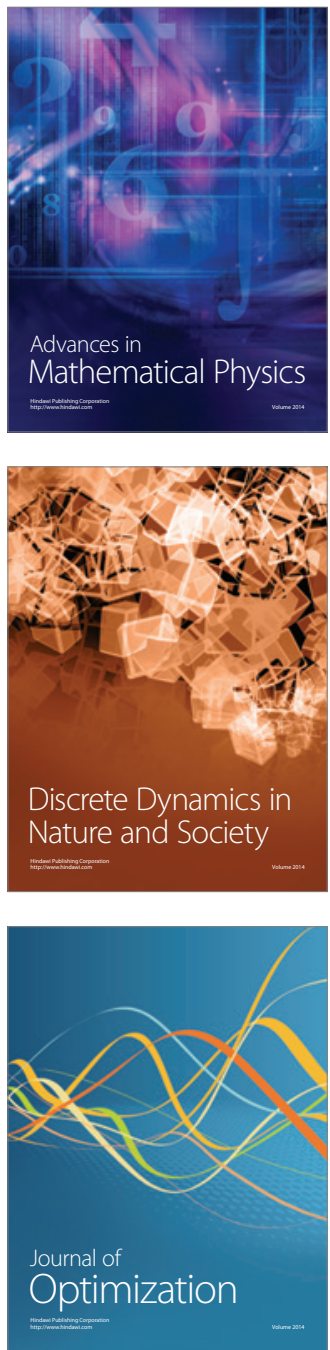